\title{
Da Ópera para o Salão: o repertório doméstico do século XIX'
}

\author{
Guilherme A. Sauerbronn de Barros
}

\begin{abstract}
RESUMO: O projeto “Música De Salão: Presença Da Ópera Na Obra Dos Virtuoses Do Piano" tem como objetivo principal fazer um levantamento histórico-analítico do repertório de salão do século XIX, com ênfase em obras virtuosísticas baseadas em repertório operístico. Dentre os objetivos propostos estão: catalogação das obras por autor e data; levantamento histórico biográfico dos autores; estudo das características formais, por meio da análise musical, bem como das características idiomáticas e dos recursos técnicointerpretativos empregados nas obras.
\end{abstract}

PALAVRAS-CHAVE: música de salão; ópera; virtuose; piano; Brasil

\section{INTRODUÇÃO:}

Boa parte do repertório de salão da segunda metade do século XIX consistia em fantasias sobre arias de ópera, reduções e adaptações de peças orquestrais. Muitos autores eram virtuoses do piano e procuravam inspirar-se no estilo de Liszt e Chopin. As edições e coletâneas para piano tornaram-se um importante fator na formação do gosto musical da época, ao entrar nos lares da recém formada burguesia para serem executadas pelas "moças de família".

A proposta deste projeto é fazer um estudo de obras representativas deste repertório; trata-se de material pouco conhecido que, através de análise e catalogação, bem como do levantamento da história das obras e autores constantes, fornecerá um quadro representativo de um momento significativo da história do piano no Brasil.

Numa primeira etapa, será investigado o contexto histórico e sócio-cultural dos salões burgueses, na Europa e no Brasil. Se a ópera era o grande acontecimento social do século XIX, por outro lado, os salões burgueses eram um importante ponto de reunião das famílias burguesas. Esses dois espaços não eram estanques e um dos elementos de ligação entre a coletividade dos teatros e o espaço familiar dos sobrados era o repertório pianístico, fortemente calcado em temas e motivos operísticos. Neste sentido, é como se o salão fosse a contrapartida da ópera, o outro lado da moeda.

\footnotetext{
1 Título do Projeto de Pesquisa: "Música de Salão: presença da ópera na obra dos virtuoses do piano" (CEART/UDESC); Orientador: Prof. Dr. Guilherme Sauerbronn de Barros; Bolsista PROBIC: Willian Fernandes de Souza; Participante Voluntário: Alexandre Gonçalves (aluno do PPGMUS).
} 


\section{CONTEXTUALIZAÇÃO HISTÓRICA}

Na virada do século XVIII para o XIX, já se observava "a decadência do uso do violão como principal instrumento acompanhador dos saraus familiares no Rio de Janeiro (...). O sociólogo Gilberto Freyre liga o fato ao panorama maior das transformações urbanas da primeira metade do século passado, onde se inscreve a passagem de um Brasil rural, patriarcal, feudal, para o mundo burguês, que vai se concretizando na 'aristocracia dos sobrados'." (FARIA, 1996: 67)

Cabe aqui explicitar que o "panorama maior das transformações urbanas" assinalado por Gilberto Freyre, se insere num processo ainda mais amplo de "(...) transformações sociais, políticas e econômicas ocorridas na Europa a partir do final do século XVIII, determinadas pela nascente industrialização e pelas novas modalidades de exercício do poder." (MURICY, 1988: 14) O sucesso da integração do Brasil à nova realidade dependia de uma transformação do modo de vida do brasileiro, da "produção de um novo tipo de indivíduo e de população, necessário à existência da sociedade capitalista nascente e à eficácia política do poder estatal." (ibid: 27)

O novo modo de vida, burguês e urbano, ao chegar no Brasil confrontou-se com uma sociedade bastante rústica, fundada principalmente na propriedade rural, no modelo familiar patriarcal e nas relações escravocratas. O poder latifundiário, das grandes famílias rurais, "manifestava-se nos rituais públicos das festas religiosas. A família não recebia para festas privadas, não tinha o hábito dos salões." (ibid: 55) Com a urbanização, gradualmente essa elite passa a abrir os "salões dos sobrados para as reuniões 'burguesas', onde eram tramadas negociatas, intrigas e alianças políticas." (ibid: 55) O piano foi um beneficiário direto dessas mudanças, pois nos salões ele ocupava um lugar de destaque. Comercializado no Rio de Janeiro desde 1810, tornou-se uma importante peça do mobiliário doméstico, conforme nota Mario de Andrade:

\footnotetext{
"A expansão extraordinária que teve o piano dentro da burguesia do Império foi perfeitamente lógica e mesmo necessária. Instrumento completo, ao mesmo tempo solista e acompanhador do canto humano, o piano funcionou na profanização da nossa música, exatamente como seus manos, os clavicímbalos, tinham funcionado na profanização da música européia. Era o instrumento por
} 
excelência da música do amor socializado com casamento e bênção divina, tão necessário à família como o leito nupcial e a mesa de jantar." (ANDRADE, 1991: 12)

Além dos salões, outro grande evento social da época era a ópera. Quando da chegada da corte ao Brasil em 1808, a sociedade portuguesa, italianizada nos seus gostos artísticos, vivia intensamente as temporadas líricas. A Família Real trouxe em sua comitiva cantores italianos e deu todo o apoio necessário para que o hábito de freqüentar a ópera aqui se estabelecesse, prestigiando com a sua presença todos os espetáculos importantes. A ópera não era apenas um acontecimento musical. Era um evento de extrema importância social, cada camarote um palco em miniatura, onde os notáveis podiam ver e serem vistos. Era, em suma, parte fundamental da engrenagem que movia a sociedade.

Em resposta ao sucesso das temporadas líricas e ao aumento das vendas de pianos no Brasil, crescia também o mercado de partituras: em 1829 "J. Christian Müller, mestre, consertador e afinador de piano (...) anuncia que pretende 'mandar abrir uma chapa para uma coleção de música para piano, tirada dos seguintes autores: Rossini, Mozart, Haydn, Beethoven, C. M. de Weber, Gelinek, Tolbecque, Boldoin, Conde de Oginski, etc.'" (ANDRADE, 1967, v.1: 135) São obras derivadas, em parte, do repertório operístico e também de compositores que faziam sucesso em Paris.

Foi fundamental o papel das editoras e lojas de música para a consolidação do gosto musical caracteristicamente urbano no século XIX. Em 1837, o mesmo J. Christian Müller, inaugurava sua "Biblioteca de Aluguel", na Rua do Ouvidor n 36. Com uma lista de mais de mil e quinhentas peças, a biblioteca oferecia "não só as [músicas] antigas como as mais modernas, tanto instrumentaes como vocaes" (Catálogo da Biblioteca Musical de J. C. Müller e H. E. Heinen, p. 6 in MAGALDI, op. cit: 123) As chamadas “modernas" eram em sua maioria "variações e fantasias sobre temas operísticos. Escritas por virtuoses do piano, (...) a maioria era para piano solo ou a quatro mãos." (Ibid: 123)

Outro fenômeno cultural da época foi o surgimento de "Sociedades Musicais". Originalmente criadas para preencher o vazio deixado pelas interrupções ocasionais das temporadas operísticas, foram pouco a pouco adquirindo existência autônoma. Na Sociedade Beneficência Musical, criada em 1834 e tendo como diretor Francisco Manoel da Silva (que se consagraria como autor do Hino Nacional Brasileiro e fundador do Conservatório) os concertos eram mensais e constavam de peças curtas executadas por 
diversos músicos. Transcrevemos aqui o programa de uma dessas Partidas Musicais, como eram chamadas. Trata-se de uma coleção de trechos de ópera, intercalados por variações instrumentais, também estes sobre temas operísticos.

"Academia de Música Vocal e Instrumental" em benefício da Sociedade Beneficência Musical em 16 de outubro de 1837, no Theatro Constitucional Fluminense.

$1^{\mathrm{a}}$ Parte 1-Nova Abertura de "Lestocq" de Auber

2-Introdução de "Coradino": Gabriel F. da Trindade, João dos Reis Pereira e côro

3-Variações para Corne Inglês de Januário da Silva Arvelos: Francisco Motta

4-Dueto de "Bianca" e "Faliero" de Rossini: Elisa Piacentini e Candido Ignácio da

Silva

5- Variações para Clarinete: João Bartolomeu Klier

6-Aria de Tancredi de Rossini: João Francisco Fasciotti

7-Introdução de Semiramide de Rossini: Elisa Piacentini, Candido Ignácio da

Silva, João dos Reis Pereira e côro

$2^{\text {a }}$ Parte 1-Nova Abertura do "Le Cheval de Bronze" de Auber

2-Aria de Vaccai: Candido Ignácio da Silva e côro

3-Allegro do Concerto para pianoforte de Kalkbremner: Francisco Muniz

4-Dueto de Tancredi de Rossini: João Fasciotti e Gabriel Fernandes da Trindade

5-Novas Variações para "corneta de chaves" de Candido Ignácio da Silva:

Desiderio Dorison

6-Introdução de Adina de Rossini: Candido Ignácio da Silva, Gabriel Fernandes da

Trindade e joão dos Reis Pereira

*nota: Ingressos à venda na casa de Candido Ignácio da Silva, Rua da Alfândega, 50" (ibid.: 41)

Na metade do século chegam ao Brasil os primeiros virtuoses do piano. O primeiro foi Thalberg, que aportou no Rio de Janeiro em 1855 e causou enorme fascínio com sua técnica brilhante. Era conhecido como rival de Liszt e consta que fora elogiado por Clara Schumann, Hans Von Bülow, Mendelssohn e pelo próprio Schumann.

Suas fantasias sobre temas operísticos serviram de modelos para muitos de seus contemporâneos. Conhecedor de técnicas contrapontísticas, dominando os recursos técnicos do piano com maestria, Thalberg trazia para o piano sonoridades orquestrais insuspeitadas. 
Seus concertos foram incansavelmente louvados pela crítica e pelo público e suas obras permaneceram nas listas dos editores e no repertório dos pianistas até o final do século: "Antes de Thalberg, o piano era geralmente encarado como instrumento de salão para acompanhar cantores, mas, após sua visita, passou a servir como meio para composições mais sérias." (ibid.: 250)

Os concertos promovidos pelas sociedades musicais trazem agora uma novidade: percebe-se uma exaltação da figura do concertista, que tem para si um espaço maior e mais exclusivo na apresentação.

"Lyrico Fluminense: Sexta feira, 6 de julho de 1866

Concerto de ARTHUR NAPOLEÃO

e Sr. Vasques, artista do Theatro Gymnasio, em uma de suas melhores cenas cômicas.

Grande Fantasia sobre motivos da ópera Luiza Miller, composta e executada por ARTHUR NAPOLEÃO.

Peça em 4 atos, Heloisa Paranquet do Theatro Gymnasio

Entre o segundo e terceiro atos

Fantasia-Concerto sobre motivos da ópera Africana de Mayerbeer, para piano e grande orquestra, composta e tocada por ARTHUR NAPOLEÃO.

Após a peça Heloiza Paranquet, será apresentado o Grande Capricho sobre a valsa e dueto da ópera Fausto composto e tocado por ARTHUR NAPOLEÃO." (ibid.: 42)

Muitos dos virtuoses eram também editores de música. Arthur Napoleão, pianista português que se apresentou pela primeira vez no Brasil aos quatorze anos, fixaria residência no Rio de Janeiro em 1868 e fundaria uma casa de música em parceria com Narciso José Pinto Braga. Esta viria a tornar-se uma das mais importantes editoras de música do século XIX no Brasil: Narciso \& Arthur Napoleão. Negócio próspero e de grande importância social, as editoras de música forneciam o repertório doméstico cumpriam a função de formadoras do gosto musical da burguesia. 
Outro virtuose que marcou o cenário musical brasileiro do XIX foi o norteamericano Louis Moreau Gottschalk. A valorização de elementos tipicamente nacionais era uma característica de sua música, que explorava desde ritmos regionais de New Orleans até batuques tropicais. Apresentando-se pela primeira vez em 1869 no salão da Sociedade Philarmônica Fluminense, seus concertos tiveram sempre os ingressos esgotados com antecedência e foram infalivelmente enobrecidos com a presença da Família Real. Em reconhecimento à calorosa acolhida, Gottschalk compôs sua Grande fantaisie triomphale sur l'hymne national brésilien, Op. 69. "Uma vez que os virtuoses tocavam apenas o repertório por eles composto, as vendas das partituras desse repertório "decolavam" após suas visitas. Além disso, essas publicações inspiravam peças similares entre os compositores locais" (Ibid: 171).

Nota-se, portanto, uma forte circulação do repertório operístico através dos diferentes espaços musicais da época: começando no teatro, passando pelas sociedades musicais e adentrando os salões das casas. Ao fundo, a figura arquetípica do virtuose, que utiliza em suas fantasias e variações este mesmo repertório, em releituras de grande efeito instrumental.

\footnotetext{
"Enquanto nos salões e no grande número de sociedades musicais surgidas na segunda metade do século XIX, os bailes, saraus e concertos privados tornavam-se grandes acontecimentos sociais, a ópera tomava conta dos teatros do Rio de Janeiro, constituindo-se, talvez, na mais importante expressão da música erudita no Brasil do século XIX, fosse ela européia ou nacional, influenciando todo o meio musical, inclusive os pianistas e a música por eles praticada." (FONSECA, 1996: 24)
}

No entanto, na Europa, a partir da segunda metade do século XIX o gosto pela ópera italiana estava ficando demodé e cedendo lugar à música "séria" dos compositores germânicos. É importante notar a ascensão da Alemanha, tanto nas artes como na política, durante esse período.

A música germânica estava de acordo com os novos ideais de "arte pura" difundidos e adotados nos grandes centros. O conceito de "boa música", em voga em Paris e trazido ao Rio por intelectuais e aristocratas, é defendido em artigo do Jornal do Commercio de 21 de julho de 1870: "O tempo das chimeras passou; a fantasia despida de sentido teve seu tempo; lugar ao verdadeiro, aos divinos chefes de obra, applaudidos e adorados do outro lado do 
equador. A hora do progresso intellectual musical soou para o Brazil..." (Jornal do Commercio, 21/07/1870 in MAGALDI, op. cit.: 83)

O repertório "leve" derivado da ópera vinha aos poucos sendo substituído pela música germânica. Essa mudança não se limitava aos concertos, mas se fazia sentir também no repertório doméstico, pois o pianismo de salão "tinha o papel de repetidor e simbolizador, em miniatura, do que ocorria musical e politicamente na sociedade." (FONSECA, op. cit.: 76)

O regime monárquico, enfraquecido pelas transformações capitalistas assistia ao crescimento do Partido Republicano, comprometido com a modernização da economia brasileira. Essa modernização implicava na substituição dos antigos grupos detentores do poder político - proprietários de terra ligados à produção açucareira decadente e ao café do vale do paraíba - por outros mais fortes economicamente e mais "modernos", no sentido de estarem mais adaptados aos métodos capitalistas de produção. O poder econômico deslocava-se para São Paulo.

A reação à antiga ordem política implicava num repúdio à ópera, manifestação artística que melhor sintetizava os valores da Monarquia. O novo regime pedia uma nova estética e, "(...) em certa medida, o piano e o concerto sinfônico simbolizaram para a Primeira República o que o canto e a ópera representaram dentro do regime monárquico." (ibid.:108)

Juntamente com a ópera, foram-se também os grandes nomes da música de salão do século XIX, nomes que outrora eram familiares e que hoje soam exóticos. Resgatar esses autores e reavaliar criticamente sua música é um dos objetivos deste projeto.

\section{REFERÊNCIAS:}

ANDRADE, Ayres de. Francisco Manoel da Silva e seu Tempo. Rio de Janeiro, Edições Tempo Brasileiro Ltda, 1967, 2 v.

ANDRADE, Mário de. Aspectos da Música Brasileira. Rio de Janeiro-Belo Horizonte, Villa Rica Editoras Reunidas Limitada, 1991

BARROS, Guilherme Sauerbronn de. "Danças Negras na Estética Nacionalista: música para piano" in Poesia Sempre, n.23, ano 13. Rio de Janeiro: Bibioteca Nacional, 2006 CERNICHIARO, Vincenzo. Storia Della Musica nel Brasile - Dai tempi coloniali ai nostri giorni (1545-1925). Milano, Fratelli Riccioni, 1926

DAHLHAUS, Carl. Analysis and Value Judgment. New York: Pendragon Press, 1983 
FARIA, Paulo Rogério Campos de. Pianismo de Concerto no Rio de Janeiro do século XIX. Tese de Mestrado, Rio de Janeiro, UFRJ, 1996

FONSECA, Anna Cristina Cardozo da. História Social do Piano-Nacionalismo

/Modernismo- Rio de Janeiro 1808/1922. Tese de Mestrado, Rio de Janeiro, UFRJ, 1996

MAGALDI, Cristina. Concert Life in Rio de Janeiro, 1837-1900. Tese de Doutorado,

UCLA (University of California), 1994

MURICY, Katia. A Razão Cética : Machado de Assis e as Questões de Seu Tempo. São Paulo, Companhia das Letras, 1988

NEUMANN, Frederick. New Essays on Performance Practice. Rochester: University of Rochester Press, 1989

WEBER, Max. Os Fundamentos Racionais e Sociológicos da Música. São Paulo, EDUSP, 1995 